\title{
Sobre a produção de valor: a recente circulação do poema "Viva Vaia", de Augusto de Campos Luciana Salazar Salgado ${ }^{1}$
}

Este artigo se inscreve nos estudos das materialidades da cultura, notadamente nas vertentes que se têm ocupado de considerar as inscrições materiais do literário. Assume, para tanto, uma perspectiva discursiva, o que implica focalizar os modos de "partilha do sensível" (Rancière, 2009) que se estabelecem quando um texto literário - vale dizer, reconhecido como tal - se põe em circulação. Trata-se de abordar a política estética que preside um regime, um funcionamento de valores co-construídos em um

sistema de evidências sensíveis que revela, ao mesmo tempo, a existência de um comum e dos recortes que nele definem lugares e partes respectivas. Uma partilha do sensível [que] fixa, portanto, ao mesmo tempo, um comum partilhado e partes exclusivas. Essa repartição das partes e dos lugares se funda numa partilha de espaços, tempos e tipos de atividade que determina propriamente a maneira como um comum se presta à participação e como uns e outros tomam parte nessa partilha (Rancière, 2009, p. 15).

Trata-se de pôr em relevo a constituição das trocas sociais em que há participação do literário: no confronto entre imaginários que o instituem como tal, mais precisamente como material de valor literário. Com isso, também se põe em relevo a própria noção de valor literário, que se produz num intrincado feixe de discursivizações. A esse feixe - que julgamos imprescindível estudar se pretendemos contribuir para a compreensão de fenômenos atuais sem apenas reproduzir a teoria já produzida no campo - chamamos espaço associado (Maingueneau, 2006). Assim, leva-se em conta uma implicação histórica de práticas, memórias e institucionalidades:

A doxa advinda da estética romântica privilegia a singularidade do criador e minimiza o papel dos destinatários, bem como o caráter institucional do exercício da literatura, sendo a instituição na maioria das vezes considerada um universo hostil à criação. É

${ }^{1}$ Doutora em linguística e professora do Programa de Pós-Graduação em Estudos de Literatura da Universidade Federal de São Carlos (UFSCar), São Carlos, SP, Brasil. E-mail: lucianasalazar@ufscar.br 
a própria estrutura do ato de comunicação literária que se vê negada dessa maneira. Contudo, para produzir enunciados reconhecidos como literários, é preciso apresentar-se como escritor, definir-se com relação às representações e aos comportamentos associados a essa condição. Claro que muitos escritores, e não os menos importantes, retiram-se para o deserto, recusando todo pertencimento à "vida literária"; mas seu afastamento só tem sentido no âmbito do espaço literário a partir do qual eles adquirem sua identidade: a fuga para o deserto é um dos gestos prototípicos que legitimam o produtor de um texto constituinte. Eles não podem situar-se no exterior de um campo literário, que, seja como for, vive do fato de não ter um verdadeiro lugar (Maingueneau, 2006, p. 89).

Essa perspectiva de investigação da circulação do literário sempre considera que há uma inscrição material correlata, ou seja, que há suportes afeitos a dadas circulações, e que esses suportes e as circulações em que se viabilizam também constituem a obra. Em síntese: o que se diz a respeito de um material literário e, sobretudo, como se diz o que se diz a respeito dele, associa-se ao próprio material literário conferindo-lhe valor. Um valor variável, posto que se erige na partilha do sensível que delimita comunidades de apreciação. E que, no atual período, caracterizado pela intensificação dos fluxos de materiais em circulação, é balizado por uma heterogeneidade típica do "mundo codificado", no qual se estabeleceu um parâmetro avalizador de caráter comunicacional: "quanto mais difícil de se integrar uma publicação nas informações acumuladas, mais original ela é, ou seja, mais interessante. E quanto menos 'original' ela for, mais confortavelmente poderá ser incorporada" (Flusser, 2007, p. 156).

O caso a seguir parece emblemático dessa discussão sobre a produção do valor, partilhada, hoje, nesses intensos fluxos nos quais se evidenciam as complexas relações técnicas, normativas e políticas em que um regime literário se delineia.

Sobre este último aspecto, o dos fluxos intensos característicos do atual período, importa registrar que é abordado aqui não de uma perspectiva semiológica estrita, mas conforme um programa de pesquisa que recorre a teorias da organização socioespacial, para as quais os objetos técnicos, entendidos como responsivos, impõem-se aos sujeitos, às práticas de subjetivação. Pode-se dizer, então, que se trata de 
uma abordagem que conecta o trabalho com os signos a um vivido (Baudrillard, 1995; Santos, 2009; Latour, 2009).

\title{
O caso Viva Vaia
}

Em 14 de junho de 2014, foi publicado no periódico paulistano Folha de S. Paulo um texto sem autoria explicitada - uma nota?, um comentário?, um fait divers? - acompanhado de um poema que seria deflagrador de manifestações variadas nas redes digitais, muitas e intensas.

A seguir, reproduzimos parte da publicação on-line - sem as duas colunas à direita, constituídas por publicidade dinâmica (que se altera conforme o dia e o usuário) e chamadas para temas afins (não seria possível, portanto, retomar a configuração exata do dia 14 de junho, o que é um dado importante sobre a dinâmica em que se inscreve o texto):

\section{Torcida que xingou Dilma gera discussão sobre insulto e crítica}

\author{
DE SÃO PAULO \\ $14 / 06 / 2014 \bigcirc 02 h 00$ \\ Quem eram os brasileiros que, com entrada VIP ou \\ ingressos muitas vezes custando acima de R\$1.00o, \\ xingaram a presidente Dilma Rousseff com palavróes \\ na abertura da Copa? \\ Mesmo sem pesquisa na porta do Itaquerão, não \\ parece arriscado intuir. No Datafolha, é \\ principalmente o público com renda familiar acima \\ de dez salários mínimos.
}

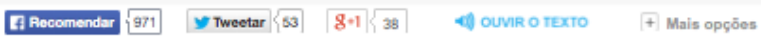

MRV

Fale agora com um atendente e simule seu financiamento.

Com 33\% de aprovação, Dilma não está numa boa fase. Em São Paulo, vai ainda pior, $23 \%$. Na cidade, $19 \%$. E entre os paulistanos com renda alta, $11 \%$ (aí, 2 em cada 3 acham seu governo ruim ou péssimo).

Vale xingar? Liberdade de expressão ou falta de educação? É possível discutir os limites da vaia. Só não dá para dizer que, naquele Itaquerão, a ofensa foi uma surpresa.

Opinião: Palavrões vieram de gente que tem dinheiro, mas sem civilidade Opinião: Xingamento de 'yellow blocs' da elite foi machista e vergonhoso Opinião: A democracia também existe para aqueles que não fazem "mu"! 


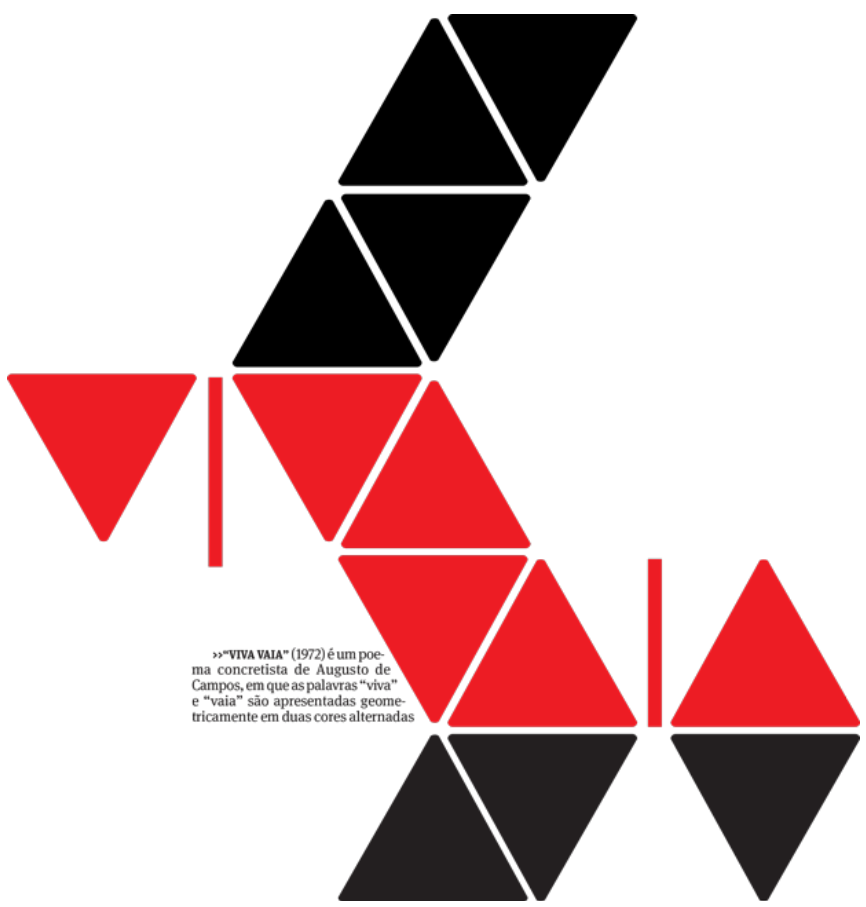

Figura 1 - Reprodução de parte da página on-line da Folha de S. Paulo, publicada em 14 de junho de 2014. Screenshot em: 27 nov. 2014. ${ }^{2}$

A vaia sobre a qual se fala no texto jornalístico aconteceu na abertura da Copa do Mundo, no lendário Maracanã, quando se realizava o jogo inaugural de um campeonato esportivo atravessado por questões político-partidárias desde a definição do Brasil como sede de sua

\footnotetext{
${ }^{2}$ Disponível em: 〈http://goo.gl/KtHZxn>. Embora a alguns olhos possa parecer desnecessário o registro, acostumados que estão a abordar um texto como se ele valesse por si, numa abordagem material da circulação de textos, é importante notar que, nesta data, a cabeça da página em que o material acima reproduzido está aberto ao público, lê-se o título de seção "eleições 2014", e nas colunas laterais com conteúdos dinâmicos, assim como no menu horizontal acima do texto, constam entradas para tópicos relativos às eleições junto a conteúdos não permanentes, entre os quais se lê, por exemplo, no item "+livraria": "Século XXI 'choca ovos' do autoritarismo, diz cientista político"; "Para preservar a Terra, autor propõe controle da natalidade"; "O Fim do Brasil' prevê ruína econômica do país”. Indícios da complexa composição de uma página online, reveladores de um posicionamento editorial que estabelece cadeias semânticas variáveis conforme a articulação desses componentes. O "mesmo" texto é reinscrito em diferentes composições de página, que se sucedem "infinitamente".
} 
vigésima edição. Sabidamente, longe de ser uma unanimidade, a Copa do Mundo 2014 transformou cidades, estabeleceu diversas relações público-privadas na produção de infraestruturas e pôs, na ordem do dia, uma reflexão sobre a identidade do brasileiro: sua hospitalidade, sua alegria, sua falta de pontualidade, sua incapacidade de gerir megaprojetos... Mitos e traços de cultura se entrelaçaram em acaloradas discussões no espaço público.

Para nossos propósitos aqui, entre tantos tópicos dessa conjuntura que valeria a pena abordar, retenhamos dois. Primeiro, registremos a ampla circulação do autor Nelson Rodrigues nesse período: para além de sua afamada relação com o futebol, frequentemente evocada, foi retomado em sua formulação sobre o "complexo de vira-latas" do brasileiro, sintagma que figurou como condensador de muitas das discussões havidas. Mais detidamente, registremos que essa ampla circulação deveu-se em boa medida às potencialidades técnicas de difusão das redes digitais, com as quais outras redes dialogam. Essas redes fizeram chegar a muitos que nem sequer conheciam Nelson Rodrigues suas crônicas, sua dramaturgia, e distribuíram-se links variados para textos completos ou coleções de fragmentos, comentários de toda sorte sobre materiais audiovisuais que tivessem tags convocadoras de certa cadeia semântica: o brasileiro, fadado a uma posição desprezível? A crônica de Nelson Rodrigues se tornou um ponto nodal em um amplo debate.

Nesse contexto de rumor público, é que focalizamos a participação de outro material literário: o poema "Viva Vaia", de Augusto de Campos.

O que se lê na legenda proposta pela Editoria de Arte para o poema "Viva Vaia" na versão reproduzida na figura 1 permite que investiguemos o episódio na direção a que nos propusemos. Nela se diz: “VIVA VAIA (1972) é um poema concretista de Augusto de Campos em que as palavras 'viva' e 'vaia' são apresentadas geometricamente em duas cores alternadas". Essa formulação seria uma legenda para uma imagem ou uma chave de leitura para um poema?

Diante dessa dupla possibilidade, cabe pensar em que medida um poema requer, merece ou permite que se diga o que ele é. Seria usual publicar um poema com o nome do autor, título do livro de que faz parte ou plataforma em que se produziu. Seria, talvez, justificável publicar uma legenda que dá chave de leitura a um poema concretista, na medida em que, passada a vaga e imersos que estamos numa cultura 
imagética que banalizou procedimentos sofisticados de outrora, fosse o caso de "avisar" incautos do que se trata. Para o momento, registremos que o nome do poeta e a própria designação "poeta", nesta configuração, vêm avalizar a participação de um poema na diagramação da página, compondo-a com um texto que ninguém assinou e com um infográfico. Logo abaixo dessa "imagem legendada", vê-se outra, depois da qual está o botão para inserção de comentários:

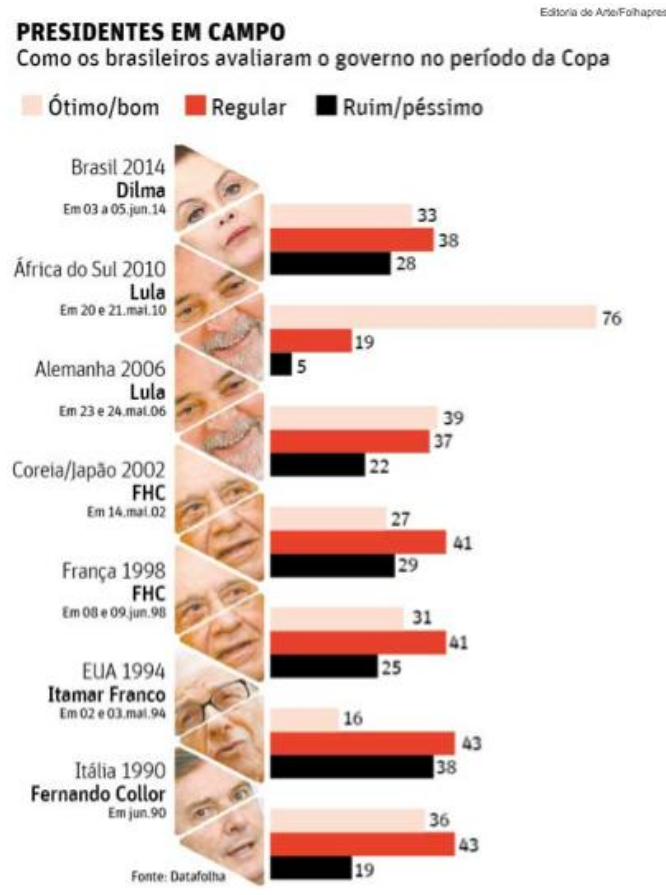

Figura 2 - Reprodução da continuação da página on-line apresentada na figura 1. Screeshot em: 27 nov. 2014.

Uma cadeia semântica se consolida: trata-se de pensar articuladamente a Copa do Mundo e a popularidade de presidentes brasileiros. Podemos ver nessa composição o modo como as técnicas intensificadoras da difusão da informação se conjugam a técnicas facilitadoras de edições de todo tipo de informação, produzindo infográficos de alta potência sígnica. Os gráficos veiculados em ambientes ditos jornalísticos organizam informações em complexos 
jogos de cores, formas e frequentemente, como neste caso, de imagens com efeitos documentais, aqui produzidos, sobretudo, pela evocação das fotos $3 \times 4$, típicas de documentos pessoais.

Decerto poderíamos dizer muito ainda sobre os aspectos da composição dessa página de jornal. Nesta altura, porém, queremos acrescentar outro dado: na diagramação da página Painel do Leitor, que homologa textos variados, de diferentes leitores, figura a carta que Augusto de Campos escreveu em réplica à publicação de seu poema:

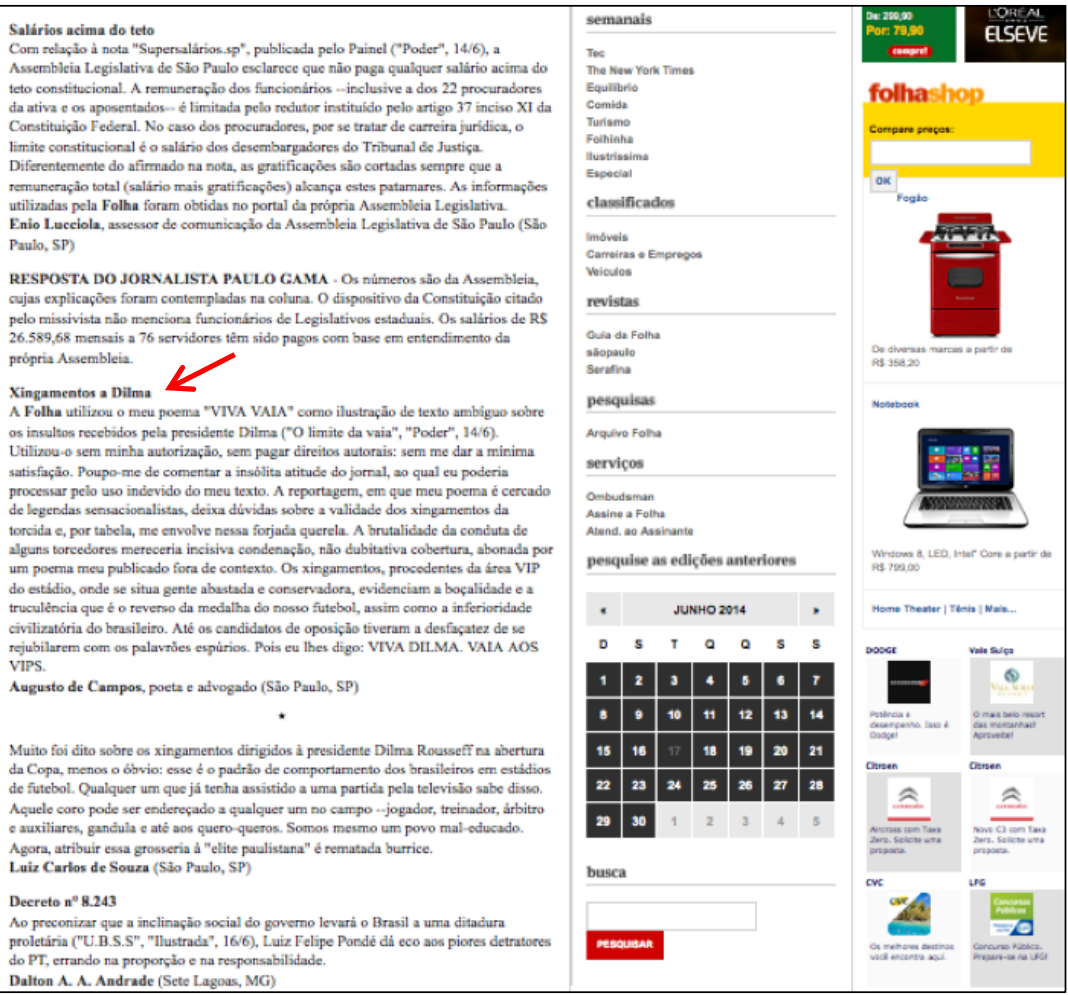

Figura 3 - Publicação, no "Painel do Leitor" e sem destaque, da carta de Augusto de Campos, em 17 de junho de 2014. Screenshot em: 24 ago. 2014. 


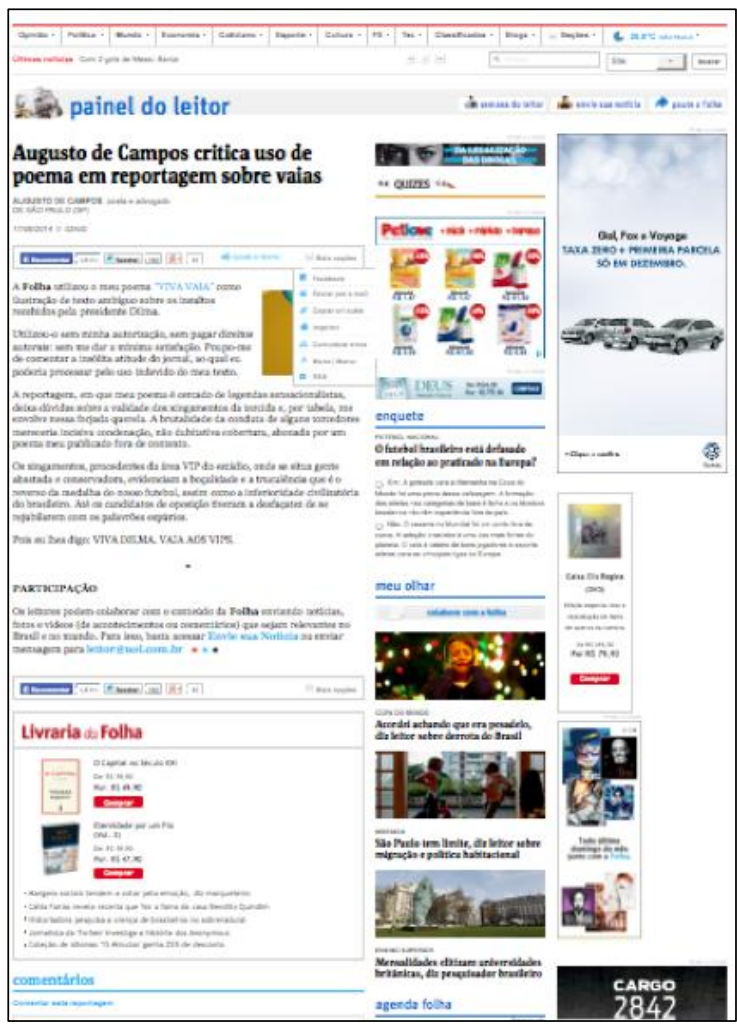

Figura 4 - Página com a publicação no "Painel do Leitor" e com destaque, da carta de Augusto de Campos, em 17 de junho de 2014. Screenshot em: 24 ago. 2014.

E, para que se possa ler a carta tal como foi publicada, um recorte: 


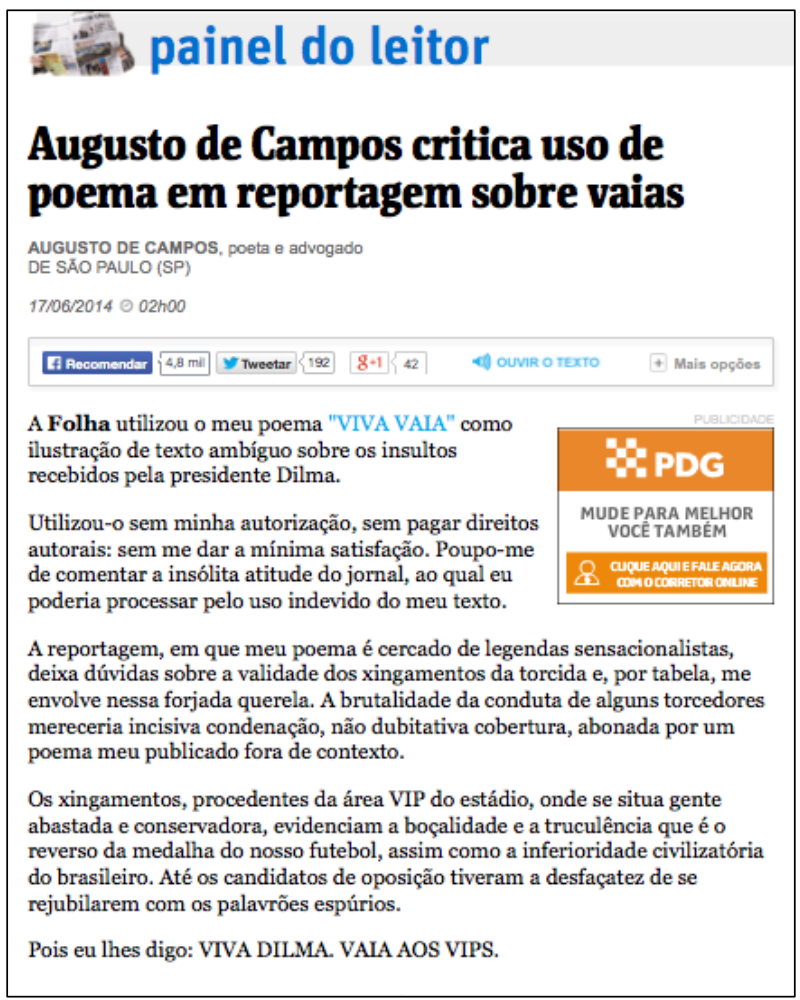

Figura 5 - Recorte da página com a publicação, no "Painel do Leitor" com destaque, da carta de Augusto de Campos, em 17 de junho de 2014. Screenshot em: 28 nov 2014.

Detenhamo-nos aqui nos diferentes modos de apresentar a carta: em um mesmo dia é publicada sem destaque e com destaque. Primeiro com o título "Xingamentos a Dilma", em meio a registros de outros leitores sobre outros temas; depois, com um título longo que organiza a carta como uma "crítica" a um "uso de poema" em "reportagem sobre vaias". Com essa modalização na segunda publicação, o jornal talvez procurasse fazer jus às reivindicações do poeta, oferecendo a sua carta diagramação semelhante à da referida "reportagem", e garantindo, com isso, a imagem de um espaço plural, aberto ao confronto. Uma defesa, talvez? De todo modo, parece importante registrar que, mesmo aí, o destaque da carta convive com uma farta oferta de produtos, serviços, 
notícias... apelos variados que compõem um conjunto de forte teor apelativo, e que produzem uma sintaxe dispersiva.

Por que duas versões do texto publicadas no mesmo dia? Parece possível supor que a decisão editorial buscava estar em sintonia com um movimento mais amplo: desde o dia anterior, 16 de junho, muito rapidamente, espalhou-se em diversas redes, notadamente na blogosfera, a carta de Augusto de Campos acompanhada de outros enquadramentos. Em diversos blogs (além de chamadas no Facebook e no Twitter), afirmava-se que o jornal não teria publicado a carta do poeta senão em setor restrito a assinantes. Por isso, ela estava sendo vazada na rede a pedido do próprio autor. Assim, por exemplo:

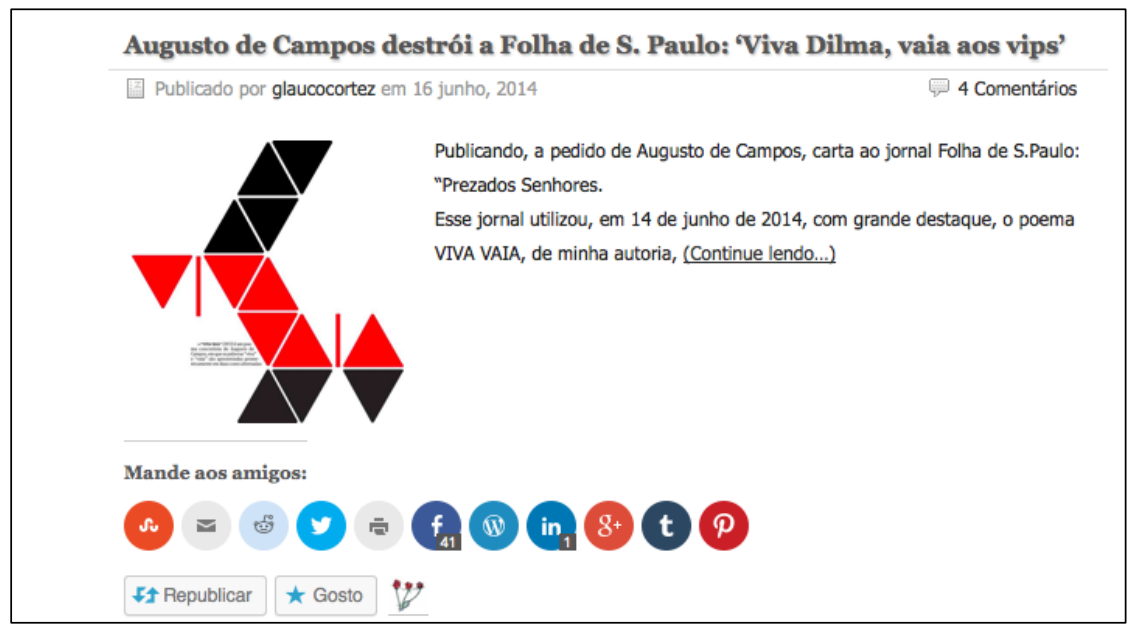

Figura 6 - Exemplo da publicação da carta de Augusto de Campos na blogosfera. Fonte: Blog de Glauco Cortez. Screenshot em: 24 ago. 2014.

Examinemos os expedientes de mediação editorial que regem a difusão dessa carta fora do jornal. No que diz respeito ao tratamento dos títulos a ela atribuídos, verificamos que não só o jornal orienta a leitura da carta nas duas versões que publica, mas cada blogueiro que a republicou, no contexto altamente partidarizado em que se inscreviam essas retomadas, também apresenta a carta de uma posição claramente definida por títulos, chamadas, olhos: no exemplo acima, em "Augusto de Campos destrói a Folha de S. Paulo" fica evidente a alusão a um posicionamento que rivaliza com o do jornal. 
Como se pôde verificar antes, durante e depois da Copa do Mundo, esse jornal trabalhou fortemente contra uma das candidaturas no pleito eleitoral em curso. ${ }^{3}$ Isto configurou o móbil do que se divulgou na blogosfera, que pôs em circulação, junto à difusão da carta de Augusto de Campos, denúncias, charges e reflexões sobre esse jornal e, mais amplamente, sobre o jornalismo político em períodos eleitorais. A reivindicação do poeta sobre seu poema estava eivada pela disputa político-partidária que se renovou com a circulação de sua carta.

No que tange à formatação da carta em suas duas versões publicadas no jornal, verifica-se uma manobra editorial de suma importância: a passagem do texto original "Prezados senhores" desapareceu, e a referência "Esse jornal" foi substituída por uma espécie de logomarca (Folha, em negrito). Com essa alteração na dêixis discursiva, alteram-se os interlocutores envolvidos. Os editores do jornal a quem se dirigia a carta não são mais convocados e, assim, são dispensados do confronto de que os leitores do jornal seriam testemunha. Abre-se espaço para um texto que se apresenta, então, como um registro do poeta diretamente aos leitores do jornal, o que enseja lineamentos de um espaço público democrático. Desse modo, não lemos mais uma carta em que o poeta acusa os editores de maus procedimentos, mas um registro de desagrado com a publicação do poema. Ou seja, de uma interlocução institucionalizada (poeta - editores do jornal) aberta ao testemunho de terceiros, a carta passa a um comentário de valor semelhante à "reportagem" que replica.

Registre-se outro expediente que reforça essa leitura: o título do poema passa a ser um hiperlink que remete à "reportagem" do dia 14 de junho, induzindo a certa produção de sentidos, circunscrevendo o episódio, chegando até a delineá-lo por meio de uma condução técnica, que fabrica uma dada cadeia semântica.

No caso da dispersão pela blogosfera, se tomarmos o dado reproduzido na figura 6 , verificamos que os diversos botões que permitem redistribuir a versão vazada da carta indiciam o quanto a blogosfera é, mais do que o jornal, um espaço de multiplicação, de repercussão: enquanto o jornal pode "trancar" a carta em um painel

\footnotetext{
${ }^{3}$ Para mais detalhes sobre o trabalho desse periódico no referido período, sugerimos consulta ao banco de dados Manchetômetro, um website de acompanhamento da cobertura midiática das eleições 2014 do Laboratório de Estudos de Mídia e Esfera Pública (LEMEP), sediado no Instituto de Estudos Sociais e Políticos (IESP) da Universidade do Estado do Rio de Janeiro (UERJ). Disponível em: <http://www.manchetometro.com.br/>. Acesso em: 28 nov. 2014.
} 
acessível apenas a assinantes, na rede aberta são muitas as formas de replicar, de avaliar, de pôr os "amigos" a par do acontecido, delineando dessa maneira o próprio acontecimento.

Em ambos os casos, é possível observar o processo de dispersão, e não só um produto dispersado. Na blogosfera, o texto de Augusto de Campos é uma carta escrita a editores que se recusaram à interlocução e que são de certo modo punidos com a ampla disseminação do documento - orientada pelos títulos das postagens que quase sempre saúdam o poeta pelo dissabor que inflige ao periódico "rival".

Nas diversas formas de dispersão, as do jornal (em que o "comentário" figura como um direito de resposta mais ou menos merecedor de destaque) e as das redes abertas (em que a carta é lida como uma declaração de alinhamento político e repúdio ao jornalismo praticado pelo referido jornal), o texto de Augusto de Campos circula assinado por um "poeta e advogado" que reivindica sua autoria conferindo ao episódio uma densidade específica: põe no centro do embate político o valor de um poema.

\section{Um poema, vários percursos}

Para assim deslocar a fronteira traçada entre a literatura, tida como domínio específico de criações e experiências, e as produções e práticas mais comuns da cultura escrita, é necessário aproximar o que a tradição ocidental separou durante muito tempo: de um lado, a compreensão e o comentário das obras; de outro, a análise das condições técnicas ou sociais de sua publicação, circulação e apropriação (Chartier, 2007, p. 11).

Entendemos que o caso Viva Vaia, tal como o apresentamos, permite propor o estudo do material literário como pertencente a um regime discursivo, isto é, o estudo da relação do material literário com suas formas de inscrição material e de circulação social, sempre implicadas e, por isso, produtoras de sentido e de valor em contextos mais amplos do que as práticas estritas de leitura ou as hermenêuticas consagradas. Dessa perspectiva, importa pensar as especificidades do poema, considerando seu pertencimento a um conjunto de procedimentos retóricos articulados a um conjunto de práticas definidoras de um posicionamento num campo. 
Devemos considerar, portanto, que o referido poema tenha estreado sua vida pública na década de 1970, tendo sido registrado em muitas ocasiões como uma homenagem de Augusto de Campos à vaia que o compositor Caetano Veloso recebeu na apresentação da canção "É proibido proibir", em sua participação na eliminatória paulista do $3^{\circ}$ Festival Internacional da Canção da TV Globo, no Teatro da Universidade Católica, em São Paulo.4 Importa, nessa orientação de estudo, que o poema de 1971, publicado em 1972, tenha sido republicado em 1979 na reunião de experiências poéticas consolidadas desde o Plano-Piloto para a Poesia Concreta (de 1958, cf. Anexo), numa formatação em preto e branco, incorporando a sua estrutura sígnica o corte da folha no encadernamento de formato códice:

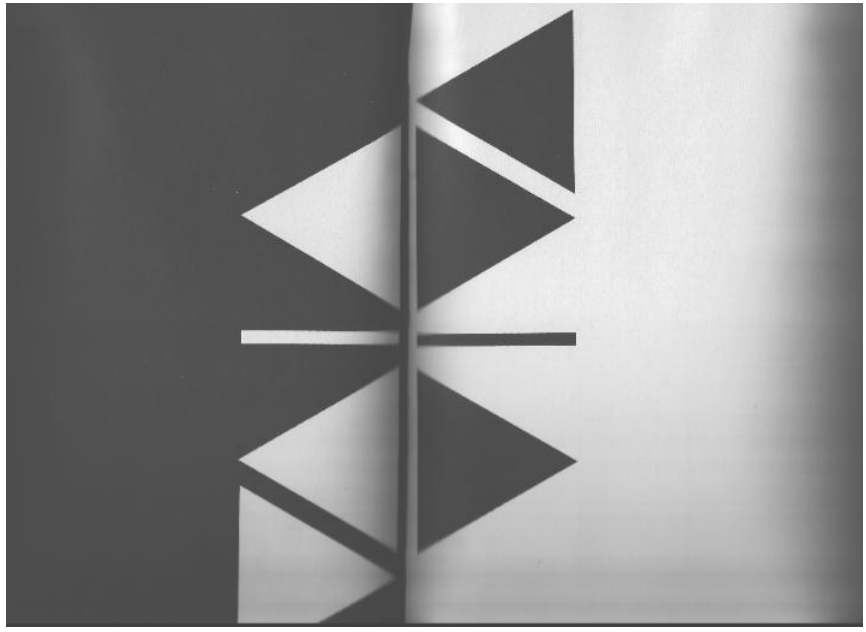

Figura 7 - Reprodução da publicação do poema VIVA VAIA no livro Viva Vaia Poesia 1949-1979, publicado pela editora Brasiliense em 1986 (s.p.).

Esse livro, que é reconhecidamente a celebração de um projeto de poesia concreta, discute o próprio formato livro, mais precisamente dos textos inscritos de um dado modo em um dado livro. Por isso, é preciso levar em conta cada uma das partes desse objeto editorial. Já na epígrafe da

\footnotetext{
${ }^{4}$ Ver, por exemplo, entre tantos registros dessa informação, a entrevista concedida por Augusto de Campos e Caetano Veloso em novembro de 2011 ao programa Metrópolis, da TV Cultura. Disponível em: <http://goo.gl/lW4PG5>. Acesso em: 28 nov. 2014.
} 
publicação de 1979, que comemora 30 anos de poesia concreta, verificam-se expedientes que reforçam a leitura do "monumento à vaia" de Campos:

Aquilo que o público vaia,

Cultive-o,

é você.

J.C.

Essa abordagem deve levar em conta também que esse poema - que propõe ver na vaia uma força vivificadora da arte - foi retomado em famosa fotografia do cinegrafista Ivan Cardoso; por sua vez, retomada com processos de edição específicos na capa de um compacto simples gravado por Caetano Veloso em parceria com Augusto de Campos (Phillips, 1979), para circular junto com o livro na sua edição comercializada pela Livraria Duas Cidades:

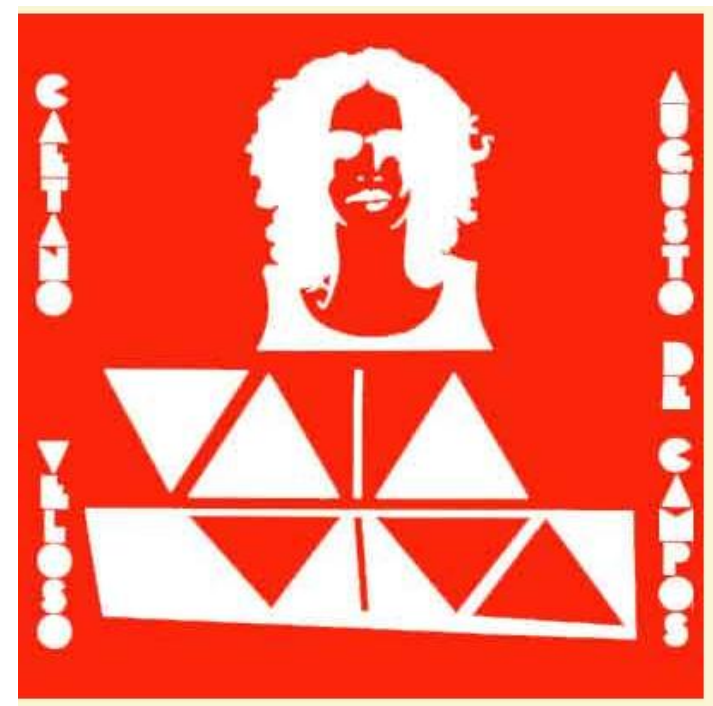

Figura 8 - Reprodução da capa do compacto simples gravado por Caetano Veloso e Augusto de Campos pela Phillips em 1979, pode ser ouvido em Discos do Brasil. ${ }^{5}$

${ }^{5}$ Disponível em: 〈http://goo.gl/qUMxZz>. 
Como se vê, trata-se de um poema que, em muitos aspectos, atende exemplarmente ao que se propunha no Plano-Piloto para a Poesia Concreta: poema-objeto sendo útil nas materializações convocadas por quem quer que seja, a serviço da verbivocovisualidade como experiência humana, libertado de qualquer origem individual e singular para ser totalidade significante no mundo urbano, puro movimento.

Há, de fato, inúmeras retomadas desse poema - em peças de roupa, na produção de mobiliário, em instalações plásticas (algumas supervisionadas pelo poeta e registradas como obras derivadas), em performances (muitas delas postadas no Youtube; em alguns casos, ainda carentes de legitimação).

Isso constatado, poderíamos dizer que o jornal que o retoma em sua composição de página não faz senão participar desses percursos, de que são passíveis todos os textos públicos e, no caso dos poemas concretos, são mesmo sua razão de ser: "tensão de palavras-coisas no espaço-tempo". Diante dessa condição constitutiva do poema, a carta publicada - sem destaque em acesso restrito, depois com destaque como réplica informativa a uma reportagem e ainda como peça político-partidária - deixa rastros de leitura que refazem a própria relação do poeta com seu poema, autorizando cada um dos leitores do poema e da carta a refazê-la também.

Quando Augusto de Campos escreve "meu poema" ou "sem minha autorização e sem pagar direitos autorais" e alega que "poderia processar o jornal", fala o poeta ou o advogado? Quando reclama do poema "cercado de legendas sensacionalistas", indignado por se ver "envolvido nessa forjada querela", fala o advogado ou o poeta? Quando acusa o jornal de ter "abonado" "a brutalidade da conduta de alguns torcedores" com o poema "publicado fora de contexto", fala um poeta que abriu mão da autonomia do poema-objeto que deve ser uma "responsabilidade integral perante a linguagem" porque, como cidadão, não partilha da bruta expressão reproduzida no jornal? Quando, diante da vaia havida, julga conservadores, boçais e truculentos aqueles dos quais marca distância ao propor "VIVA DILMA. VAIA AOS VIPS", responde à grosseria da vaia com um novo poema? Fala, aí, um brasileiro? Um eleitor? Quando a categoria VIP é alçada ao valor quase ideogramático com que a sonoridade e a visualidade do enunciado se projetam, estamos de volta ao projeto 
concreto de "criar problemas exatos e resolvê-los em termos de linguagem sensível"?

Essa problemática da autoria, que tem larga tradição em muitos campos de saber, não cessa de reaparecer. Aqui, é deflagrada pelos expedientes de mediação editorial típicos da ciberculura, uma cultura de interface, colaborativa, de partilha, de remixagem. A cibercultura, cultura hegemônica na contemporaneidade, se produz no batimento entre uma tecnosfera constituída por dispositivos ubíquos e universalizantes e uma psicoesfera contituída por disposições fluidas e dúcteis, do que resulta uma potência difusora sem precedentes ${ }^{6}$.

Com essa orientação não estritamente semiológica, podemos entender que essa dinâmica cultural não coincide com o ciberespaço. Este é feito de conjuntos de sistemas de objetos de alta condutibilidade informacional (sendo a internet um ambiente que os interliga) e sistemas de ações de grande vigor comunicacional (como os usos das diversas plataformas de partilha). Assim, o ciberespaço é entendido como produtor de disposições que irrompem em uma cultura que o ultrapassa, isto é, a cibercultra não se restringe a ele. Afeita a protocolos que dão fluidez aos conteúdos informacionais, a cibercultura se impõe como um funcionamento cultural mais amplo: uma sucessão de lógicas padronizadoras viabiliza fluxos crescentes de informação, acelerando os processos de transmissão.

Vista assim, a cibercultura é uma cultura que transcende a conexão direta com os objetos técnicos digitais, afetando conjuntos de sistemas de objetos não digitais e ações não diretamente relacionadas às redes informáticas, afetando normas e comportamentos. Os quais, evidentemente, recaem sobre os mecanismos do ciberespaço, estabelecendo uma articulação inextricável, e não uma relação biunívoca.

O caso Viva Vaia não seria exatamente um caso, se essa alta potência difusora que configura a cibercultura não tivesse produzido o volume de rumor público que, afinal, fez do uso "jornalístico" de um poema ponto nevrálgico numa disputa política fortemente partidarizada na conjuntura da Copa do Mundo de 2014.

Nesse contexto, VIVA VAIA se refaz com as palavras "viva" e "vaia" contrastando em uma nova sintaxe geometrizada: "viva" é tópico do

${ }^{6}$ Tecnoesfera e psicoesfera são noções propostas pelo geógrafo Milton Santos, desdobradas em diversas partes de sua obra. Para detalhamentos acerca de sua pertinência no estudo dos fluxos de texto característicos da contemporaneidade, ver, por exemplo, Salgado; Antas Jr. (2011) e Salgado (2013). 
primeiro enunciado; "vaia", do segundo, e já não recaem uma sobre a outra. Na formulação de fecho da carta, "viva" se refere a "DILMA", a Presidente da República vaiada; "vaia" se refere a "VIPS", os vaiadores do Maracanã. Nos anos 1970, esse poema celebrava a vaia, que enaltecia o vaiado (Caetano Veloso, a princípio, e todo aquele que propusesse impacto na interlocução com um público); a nova formulação celebra a vaiada, condenando a vaia. E essa forma de retomada se faz pela voz de quem assina "poeta e advogado", reivindicando sua obra ou, mais além, respeito a sua obra. A mesma voz que vaza sua própria carta na internet, apostando na criação de um ciber-rastilho característico das arenas públicas hoje.

Esse ciber-rastilho instaura um espaço associado, desencadeado, no caso em estudo, pelo fato de o poema não estar no seu espaço canônico. Ele figura como ilustração e desagrada o poeta, que reafirma sua autoria ao questionar a leitura proposta para sua obra. E o modo como o faz revela o que podemos chamar de tropismo autoral: há um gesto que procura conter os sentidos produzidos com o aparecimento do poema, um gesto radicado na conjuntura política que o atualiza.

\section{Várias vozes, um autor}

Augusto de Campos, esse nome que dá coesão a todos os elementos acima abordados, é, afinal, o autor do poema, um autor de poesia concreta, autor da carta que reclama respeito a sua obra diante das manobras de medição de uma editoria de jornal. Da perspectiva discursiva aqui assumida, entende-se disso que

A "identidade" criadora, seja qual for o ângulo a partir do qual a apreendemos, não se restringe à dificuldade em responder à questão aparentemente banal: "Quem é o autor dessa obra?" Ao invocar um nome próprio, designam-se tão-somente instáveis imbricações de instâncias que se recobrem: um estado civil, uma trajetória de escritor e um processo de enunciação cuja harmonia possível só se mantém através de uma constante fuga para a frente (Maingueneau, 2006, p. 137).

Assim, esse nome de autor se firma na medida em que associa materiais textuais como poemas, ensaios e performances a resenhas sobre esses materiais, a entrevistas concedidas, textos teóricos, prefácios, quartas-capas, palestras. De modo que, além do que se pode referir por 
espaço canônico, um espaço de gestão dos materiais literários, de sua criação e distribuição, há um espaço associado, textos do autor que não são reconhecidos propriamente como material literário, e também textos sobre o autor e sobre sua obra, que assume materialidades significantes. E é na operação conjunta desses espaços que se institui a marca autoral:

Trata-se de duas dimensões inseparáveis: construir uma identidade criadora na cena do mundo (figuração) e conferir um estatuto às unidades que constituem a Opus (regulação). A primeira tem como manifestação privilegiada gêneros de texto relativamente "autônomos", como o diário íntimo, o relato de viagem, as lembranças da infância; a segunda vincula-se mais com os gêneros paratextuais, metatextuais etc., inseparáveis dos textos que eles acompanham (Maingueneau, 2006, p. 143).

"Fronteira indecidível", nos termos de Maingueneau, que define a autoria como lugar paratópico, o "impossível lugar" que gera a tal "fuga para a frente": os procedimentos retóricos que autorizam a leitura literária de certos materiais vêm de par com a instituição de uma força gestora desses materiais, de suas formas de inscrição e, como se pode verificar no caso Viva Vaia, de uma força que gere esses materiais em consonânica com outros, que a ele se associam. Inclusive aqueles impostos por interlocutores - leitores, editores, críticos, etc. Assim,

O "espaço associado" não é um espaço contingente que se somaria a partir de fora ao espaço canônico: os espaços canônico e associado alimentam-se um do outro, sem contudo possuir a mesma natureza. Esse duplo espaço se mostra a si a mesmo no conjunto mais amplo de marcas deixadas pelo autor, o que inclui também os cadernos escolares, a correspondência amorosa, cartas dirigidas à administração etc. (Maingueneau, 2006, p. 144).

A fronteira em que se põe é indecidível porque se organiza em território discursivo cuja especificidade é a criação autoral, que implica valores atribuídos a certos tipos de material, os quais, valorados, passam a ser parâmetro para o que se entenderá por criação - e também por leitura, por edição, por crítica, etc., constelando formas mais autorizadas, menos autorizadas e não autorizadas de retomada. Trata-se de considerar que

O discurso literário não é um território compacto que gera simplesmente algumas dificuldades locais de estabelecimento de 
fronteiras, mas um espaço radicalmente duplo. Funciona com base num duplo movimento de desconexão (no espaço canônico) e de conexão (espaço associado) das instâncias subjetivas. Alguns analistas fixam sua atenção na desconexão (abordagem textualista) e outros na conexão (abordagem contextualista) [...]. Os próprios criadores se dividem entre os posicionamentos que optam maciçamente pela desconexão (Mallarmé ou os parnasianos) e os que preferem a conexão (Rousseau ou Céline), com todas as posições de negociação e de compromisso imagináveis. Esses dois movimentos são a um só tempo contraditórios e complementares, sendo a impossibilidade de estabilizar suas relações um dos motores da produção literária (Maingueneau, 2006, p. 146-147).

Nesses termos, devemos levar em conta que Augusto de Campos, "poeta e advogado" no reclamo que faz a uma editoria jornalística sobre o tratamento dado a um poema de sua autoria, é também pai de um músico com o qual trabalha (por exemplo, na nova edição do livro de 1979, que sai em 2014), é um dos famosos "irmãos Campos", companheiros de Décio Pignatari, e co-fundador de um movimento estético, é tradutor, estudioso de música, artista de longa trajetória que, desde os anos 1980, se dedica às novas mídias com propósitos artísticos e de investigação teórica, assumindo um lugar paradoxal de tradição experimental. ${ }^{7}$

Trata-se de um poeta-artista que "se arrisca", segundo seus termos, em parcerias e coletivos; lança-se ao contato com modos de produzir e meios de produção bastante variados. É um velho senhor jovialmente arteiro, atravessado por uma erudição ímpar que põe em uso lúdico, com simplicidade quase picaresca. Sua condição paratópica se produz inclusive no fato de ter um site e mostrar-se nele em textos, fotos e informações que categorizam sua produção em "poemas, sons, textos, links, clip-poemas", e informam sobre a pessoa que também é.

Registre-se que na entrada de seu site, há uma retomada do poema:

\footnotetext{
${ }^{7}$ Essa condição de tradição experimental é reivindicada de modo contundente na forma como se organiza a Biografia do poeta em seu site. Disponível em: 〈http://www2.uol.com.br/augustodecampos/〉. Acesso em: 28 nov. 2014.
} 


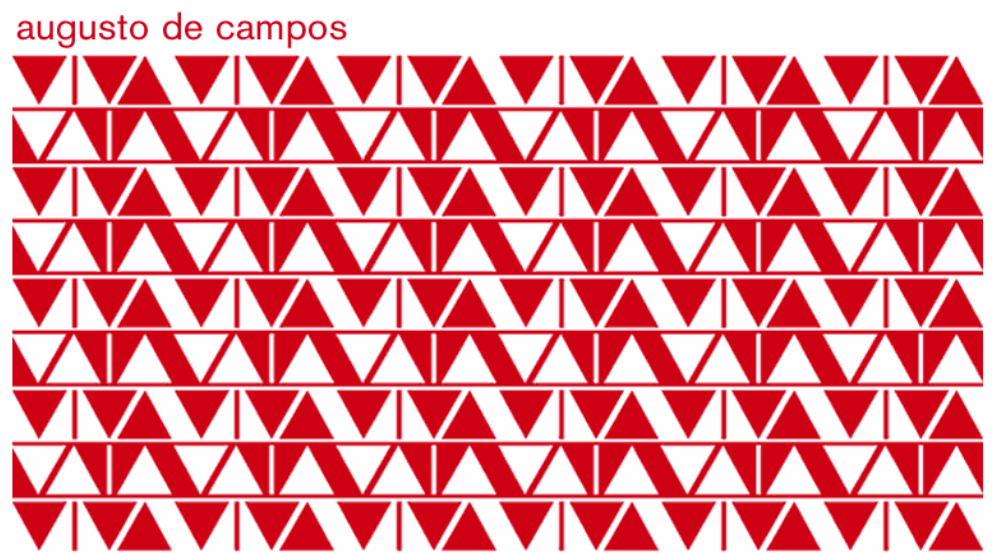

Figura 9 - Entrada do site oficial de Augusto de Campos hospedado no servidor UOL. Screenshot em: 28 nov 2014.

Com isso, o poema passa a metonímia autorizada da rede de retomadas que deslizam em variações de inscrição formal, como vimos acima - e, portanto, dos sentidos que essas variações produzem e fazem ecoar. Toda essa rede inscricional mostra que o valor poemático depende de que cada variação formal seja atribuída ou atribuível a Augusto de Campos, nome para o qual convergem, de um modo ou de outro, suas ocorrências, sendo essa convergência produzida também pelos paratextos e metatextos que o ensinam, o comentam, o citam, o referem. O espaço associado de um material literário é, assim, parte dessa obra, precisamente no que concerne a sua gestão, à gestão desse lugar paratópico de criador, que legitima a criação.

Caberia, para seguir essa trilha de investigação, descobrir como se organiza esse "site oficial", como se produz o projeto gráfico que organiza os materiais postados, em que condições cada um dos materiais postados é produzido para estar ali ou foi produzido alhures e sobe no site como um registro do que foi outra coisa, em outra circulação. E tudo isso é Augusto de Campos.

Na carta enviada ao jornal, podemos dizer que o tropismo na direção da condição de advogado se deve ao fato de Campos ter essa profissão mas, sobretudo, de essa assinatura fazer ecoarem em seu texto, com voz de autoridade jurídica, os termos relativos às fronteiras que o jornal teria atravessado indevidamente, ao fazer o "uso" que fez de seu poema. O poeta se dói por seu poema; o advogado procura protegê-lo 
dos desvios que produziram essa dor. E, mais além, o internauta contumaz sabe que é nas redes sociais que sua carta será carta-rastilho, portanto, se o que se quer é o rumor público, que sua carta seja repercutida por outras vozes, em outras formas de inscrição, necessariamente.

\section{Considerações finais}

O caso Viva Vaia nos dá ocasião para ver o material literário implicado em um discurso político fartamente mediado, condicionado por uma conjuntura específica, sem, todavia, perder-se de sua condição de regime literário. A carta de Augusto de Campos ao jornal reivindica isso: que o poema seja um poema, que não passe por ilustração de texto ou infográfico.

Seja como for, é muito interessante notar que, nesse acontecimento, aquele que assina "poeta e advogado" reclama certa propriedade dos sentidos, pois não há como reclamar a posse da inscrição material de um poema nascido no movimento estético em que nasceu, tantas vezes retomado na trajetória plástica que foi descrita acima.

O fecho da carta é uma proclamação e também uma vaia, uma nova vaia - aos que vaiaram: "Pois eu lhes digo: VIVA DILMA. VAIA AOS VIPS". E nesse "eu" cabem todas as memórias que instituem Augusto de Campos e fazem desse autor, desse lugar paratópico que instaura um posicionamento, voz autorizada a entrar no debate político para o qual foi convocado com essa publicação de seu poema.

Considerando os termos de sua carta, podemos dizer que é um posicionamento contra a boçalidade e a truculência que lê no outro, de que toma distância. Esse outro que são os torcedores da área VIP do estádio e também o jornal.

O posicionamento de Campos, firmado nos gestos de escrever uma carta, de enviá-la ao jornal, de vazá-la na rede, está estribado na condição que reinvindica - de poeta dono de seu poema. Ele se constitui na circulação do poema e da carta sobre o poema, na rede de suas retomadas, que são características de uma cultura que articula intensamente modos de apropriação dos materais literários e modos de produção do espaço a eles associado. Os comentários de terceiros, não só os nominalmente chamados a participar da gestão da obra, acabam por fazer parte dela. 
E nessa cultura estabelecida numa relação entre tecnosfera e psicosfera de alta potência difusora, acresce-se que

a sensação de precariedade de todos os textos é maior, e que há na escrita digital algo que faz mais lembrar a comunicação oral do que as várias formas de comunicação escrita, mas com um acesso aparentemente inesgotável e imediato a todo o saber do mundo. Esta sensação tem uma base, embora possa ser tão ilusória como a da fixação dos textos "autênticos" pelo papel. O que o bom senso e a reflexão sobre este percurso longo aconselham é evitar decretos lapidares sobre quando se morre, ou sobre júbilos e apocalipses. É um tempo certamente interessante, mas ainda não sabemos onde vamos (Lisboa, 2014).

Enfim, parece possível dizer que estamos diante de um poder político que está por ser entendido. Poder político tecido em uma malha de alta tecnificação, que distribui os processos de mediação entre diferentes atores, os quais podem, mais ou menos autorizadamente, retomar o material literário atribuindo-lhe diferentes valores conjunturais.

Complexifica-se, assim, o que se diz sobre ele. E também se produzem novos entendimentos da rede que o categoriza como poema, entre os quais figura um entendimento fundamental no atual período: o de que a própria singularidade de uma obra autoral se constitui coletivamente.

\section{Referências}

BAUDRILLARD, Jean ([1972] 1995). Para uma economia política do signo. Tradução de Aníbal Alves. Rio de Janeiro: Elfos; Lisboa: Edicões 70.

CAMPOS, Augusto; PIGNATARI, Décio; CAMPOS, Haroldo (1965). Teoria da poesia concreta. Textos críticos e manifestos 1950-1960. São Paulo: Invenção.

CHARTIER, Roger (2007). Inscrever e apagar. Cultura escrita e literatura. Tradução de Luzmara Curcino Ferreira. São Paulo: Editora da Unesp.

FLUSSER, Vilém ([2007] 2012). O mundo codificado: por uma filosofia do design e da comunicação. Organização de Rafael Cardoso, tradução de Raquel AbiSâmara, 3. reimpr. São Paulo: Cosac Naify.

LISBOA, Abel Barros (Org.) (2014). "Vem de longe a marca do suporte material": Uma entrevista com João Luís Lisboa. Entrevistador: Abel Barros 
Baptista. Revista do Programa de Doutormento "Estudos Avançados em Materialidades da Literatura", Coimbra, v. 2, n.1, p. 159-164.

MAINGUENEAU, Dominique (2006). Discurso literário. Tradução de Adail Sobral. São Paulo: Contexto.

RANCIÈRE, Jaques (2005). A partilha do sensível: estética e política. Tradução de Mônica Costa Neto. São Paulo: EXO Experimental; Editora 34.

SALGADO, Luciana Salazar (2013). Cibercultura: tecnoesfera e psicoesfera de alta potência difusora. In: ABRIATA, Vera Lúcia Rodella et al. (Org.). Leitura: a circulação de discursos na contemporaneidade. Franca: Unifran. p. 103-124.

SALGADO, Luciana Salazar; ANTAS JUNIOR, Ricardo Mendes (2011). A criação num "mundo sem fronteiras": paratopia no período técnico-científico informacional. Acta Scientiarum. Language and Culture, Maringá, v. 33, n. 2, p. 259-270.

Recebido em dezembro de 2014.

Aprovado em maio de 2015.

resumo/abstract/resumen

\section{Sobre a produção de valor: a recente circulação do poema "Viva Vaia", de} Augusto de Campos

\section{Luciana Salazar Salgado}

Este artigo propõe algumas considerações sobre o estatuto do material literário na contemporaneidade a partir de um estudo de caso: um poema usado como ilustração de material jornalístico. Mobilizando categorias discursivas, pretende: $i$ ) contribuir para investigações sobre os fluxos de texto na cibercultura, entendendo-a como uma cultura hegemônica no atual período, na qual se complexifica a problemática da autoria; ii) contribuir para a abordagem dos materiais literários nas suas formas de inscrição atuais ou atualizadas.

Palavras-chave: discurso literário, circulação literária, tropismo autoral, Augusto de Campos.

\section{About the production of value: the recent circulation of the poem "Viva Vaia", by Augusto de Campos}

Luciana Salazar Salgado

This article raises some questions about the status of "the literary" in contemporary society focusing on a case: a poem used as an illustration for the 
news. Based on some discursive categories, it intends to: i) contribute to researches on text flows in cyberculture, considering it as an hegemonic culture that complexifies the problem of authorship; ii) contribute to the approach of literary materials in its current or updated forms of inscription.

Keywords: literary discourse, circulation, authorship tropism, Augusto de Campos.

\section{Sobre la producción de valor: la reciente circulación del poema "Viva Vaia", de Augusto de Campos}

\section{Luciana Salazar Salgado}

Este artículo propone algunas consideraciones sobre el estatuto del material literario en la contemporaneidad desde un estudio de caso: un poema utilizado como ilustración de material periodístico. Movilizando categorías discursivas, pretende: i) contribuir para investigaciones sobre los flujos de texto en cibercultura, y se la entiende como una cultura hegemónica en el período actual, en la que se complejifica la problemática de la autoría; ii) contribuir para el enfoque de los materiales literarios en sus formas de inscripción actuales o actualizadas.

Palabras clave: discurso literário, circulación, tropismo autoral, Augusto de Campos. 


\section{Anexo \\ Plano-Piloto para Poesia Concreta}

Augusto de Campos, Décio Pignatari e Haroldo de Campos

Noigrandes, 4, São Paulo, 1958

Poesia concreta: produto de uma evolução crítica de formas dando por encerrado o ciclo histórico do verso (unidade rítmico-formal), a poesia concreta começa por tomar conhecimento do espaço gráfico como agente estrutura. espaço qualificado: estrutura espácio-temporal, em vez de desenvolvimento meramente temporístico-linear, daí a importância da idéia de ideograma, desde o seu sentido geral de sintaxe espacial ou visual, até o seu sentido específico (fenollosa/pound) de método de compor baseado na justaposição direta analógica, não lógico-discursiva - de elementos. "il faut que notre intelligence s'habitue à comprendre synthético-ideographiquement au lieu de anlyticodiscursivement" (apollinaire). eisenstein: ideograma e montagem.

precursores: mallarmé (un coup de dés, 1897): o primeiro salto qualitativo: "subdivisions prismatiques de l'idée"; espaço ("blancs") e recursos tipográficos como elementos substantivos da composição. pound (the cantos):método ideogrâmico. joyce (Ulysses e finnegans wake): palavra-ideograma; interpenetração orgânica de tempo e espaço. cummings: atomização de palavras, tipografia fisiognômica; valorização expressionista do espaço. apollinaire (calligrammes): como visão, mais do que como realização. futurismo, dadaísmo: contribuições para a vida do problema. no/brasil:/oswald de andrade (1890-1954): “em comprimidos, minutos de poesia"./joão/cabral de melo neto (n. 1920 -o engenheiro e psicologia da composição mais anti-ode): linguagem direta, economia e arquitetura funcional do verso.

poesia concreta: tensão de palavras-coisas no espaço-tempo. estrutura dinâmica: multiplicidade de movimentos concomitantes. também na música - por definição, uma arte do tempo - intervém o espaço (webern e seus seguidores: boulez e stockhausen; música concreta e eletrônica); nas artes visuais - espaciais, por definição - intervém o tempo (mondrian e a série boogie-wogie; max bill; albers e a ambivalência perceptiva; arte concreta, em geral).

ideograma: apelo à comunicação não-verbal. o poema concreto comunica a sua própria estrutura: estrutura-conteúdo. o poema concreto é um objeto em e por si mesmo, não um intérprete de objetos exteriores e/ou sensações mais ou menos subjetivas. seu material: a palavra (som, forma visual, carga semântica). seu problema: um problema de funções-relações desse material. fatores de proximidade e semelhança, psicologia da gestalt. ritmo: força relacional. o poema concreto, usando o sistema fonético (dígitos) e uma sintaxe analógica, cria uma 
área lingüística específica - "verbivocovisual" - que participa das vantagens da comunicação não-verbal,s em abdicar das virtualidades da palavra. com o poema concreto ocorre o fenômeno da metacomunicação; coincidência e simultaneidade da comunicação verbal e não-verbal, coma nota de que se trata de uma comunicação de formas, de uma estrutura-conteúdo, não da usual comunicação de mensagens.

a poesia concreta visa ao mínimo múltiplo comum da linguagem, daí a sua tendência à substantivação e à verbificação: "a moeda concreta da fala" (sapir). daí suas afinidades com as chamadas "línguas isolantes" (chinês): "quanto menos gramática exterior possui a língua chinesa, tanto mais gramática interior lhe é inerente (humboldt via cassirer). o chinês oferece um exemplo de sintaxe puramente relacional baseada exclusivamente na ordem das palavras (ver fenollosa, sapir e cassirer).

ao conflito de fundo-e-forma em busca de identificação,chamamos de isomorfismo. paralelamente ao isomorfismo fundo-forma, se desenvolve o isomorfismo espaço-tempo, que gera o movimento. o isomorfismo, num primeiro momento da pragmática poética, concreta, tendo à fisiognomia, a um movimento imitativo do real (motion); predomina a forma orgânica e a fenomenologia da composição. num estágio mais avançado, o isomorfismo tende a resolver-se em puro movimento estrutural (movement); nesta fase, predomina a forma geométrica e a matemática da composição (racionalismo sensível).

renunciando à disputa do "absoluto", a poesia concreta permanece no campo magnético do relativo perene. cronomicrometragem do acaso. controle. cibernética. o poema como um mecanismo, regulando-se a próprio: "feed-back". a comunicação mais rápida (implícito um problema de funcionalidade e de estrutura) confere ao poema um valor positivo e guia a sua própria confecção. poesia concreta: uma responsabilidade integral perante a linguagem. realismo total. contra uma poesia de expressão, subjetiva e hedonística. criar problemas exatos e resolvê-los em termos de linguagem sensível. uma arte geral da palavra. o poema-produto: objeto útil.

augusto de campos

décio pignatari

haroldo de campos

post-scriptum 1961: "sem forma revolucionária não há arte revolucionária" (Maiacóvski).

In: CAMPOS, Augusto et al. Teoria da poesia concreta. São Paulo: Invenção, 1965. 